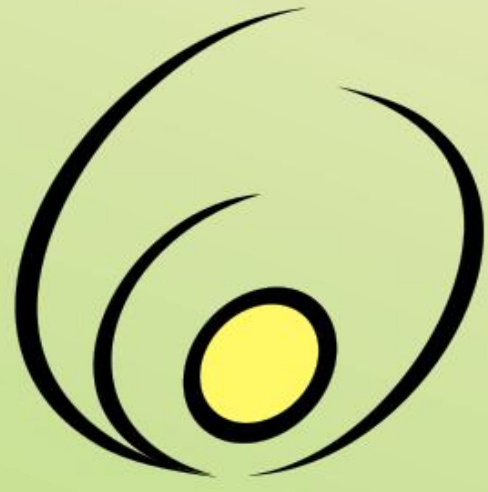

Fórum de

Pró-Reitores

de Extensão

das Instituições

\section{Públicas de}

\section{Educação Superior}

\section{Brasileiras}

\section{Odontologia itinerante na extensão universitária:} FURBMóvel - promovendo saúde bucal e

\section{cidadania}

\author{
Débora Scharf ${ }^{1,2}$ \\ Marcia de Freitas Oliveira ${ }^{3}$ \\ Aline de Oliveira ${ }^{1}$ \\ Claudia Hasselmann Schlindwein ${ }^{3}$ \\ Márcio Cristiano de Souza Rastelli ${ }^{3}$
}

Isabel Cristina Gavazzoni Bandeira de Andrade $^{3}$

Resumo: O FURBMóvel é um Programa de Extensão do curso de Odontologia da Universidade Regional de Blumenau (FURB). Foi elaborado a partir da necessidade de aproximar o acadêmico e a comunidade, visando uma formação mais crítica e humanitária. A proposta deste trabalho é descrever este Programa, destacar suas ações e discutir sobre a prática. O FURBMóvel se articula em cinco projetos tendo como público-alvo os alunos de Escolas do campo (antes denominadas Multisseriadas), alunos das Escolas Municipais que participam do Programa Mais Educação, pacientes que são atendidos nos Centros de Atenção Psicossocial (CAPS II e CAPS AD) e idosos institucionalizados na Casa São Simeão. O atendimento odontológico é realizado dentro de um veículo equipado com um consultório odontológico. Ações preventivas e educativas também são realizadas por meio de atividades lúdico-educativas. As atividades extramuros possibilitam que o acadêmico construa novos conhecimentos, adquirindo uma visão mais ampliada do mundo..

Palavras-chave: Extensão, Odontologia, Saúde bucal, Educação em saúde.

\footnotetext{
${ }^{1}$ Graduandas do Curso de Odontologia da Universidade Regional de Blumenau - FURB. Endereço: Rua São Paulo, 2171, Itoupava Seca, Blumenau/SC, CEP: 89030-000.

2 Universidade Regional de Blumenau - FURB. Endereço: Rua São Paulo, 2171, Itoupava Seca, Blumenau/SC, CEP: 89030-000. deborascharf@gmail.com (autora para correspondência)

${ }^{3}$ Professores do Curso de Odontologia da Universidade Regional de Blumenau - FURB. marciaoliveira@furb.br
} 
Itinerant dentistry practice in university extension: FURBMobile - promoting oral health and citizenship

\begin{abstract}
The FURBMobile is an Extension Program of The Dentistry Course at the Universidade Regional de Blumenau. From the need to narrow the gap between dentistry students and their community, this project aims at fostering the development of critical and humanitarian formation. The purpose of this paper is to describe this program, by highlighting their actions and to discuss the related practices. The FURBMobile is divided into five projects that target students of rural schools (formerly called 'escolas multiseriadas'), students of Municipal Schools participating in the program "Mais Educação", patients who are treated at Psychosocial Care Centers (CAPS II and CAPS AD) and elderly care center 'Casa San Simeon'. The dental care is performed in a vehicle equipped with a dental clinic. Preventive activities are also conducted by means of recreational and educational activities. Furthermore, the outreach activities make it possible for the students involved to build new knowledge and to develop a broader view of the world.
\end{abstract}

Key-words: Extension, Dentistry, Oral health, Health education.

Odontología itinerante en la extensión universitaria: FURBMóvel - La promoción de la salud bucal y la ciudadanía

Resumen: El FURBMóvel es un Programa de Extensión del Curso de Odontología de la Universidad Regional de Blumenau (FURB, Brasil). Fue desarrollado a partir de la necesidad de aproximar los académicos y la comunidad, con el objetivo de ofrecer una formación más crítica y humanitaria. El propósito de este artículo es describir este programa, destacando sus acciones y su práctica. El FURBMóvel se divide en cinco proyectos destinados a los estudiantes de las escuelas rurales (anteriormente llamados Escuelas Multiseriadas), a los estudiantes de las escuelas municipales que participan en el Programa de Pacientes "Mais Educação", a las personas asistidas en los Centros de Atención Psicosocial (CAPS II y CAPS AD) y los ancianos de la 'Casa San Simeon'. El cuidado dental se lleva a cabo por medio de un vehículo equipado con una clínica odontológica. Las actividades preventivas y educativas son también llevadas a cabo a través de actividades recreativas y educativas. Las actividades de extensión hacen posible a los académicos construir nuevos conocimientos y adquirir una visión más amplia del mundo.

Palabras-clave: Extensión, Odontología, Salud Oral, Educación para la salud.

\section{Introdução}

Segundo a legislação brasileira, a Universidade tem como função básica promover ensino, pesquisa e extensão, sendo que esta última possui um papel fundamental de conexão entre o ensino e a pesquisa, pois viabiliza o encontro entre a Universidade e a sociedade. Para uma boa formação acadêmica, o ambiente de aprendizagem não deve se limitar à sala de aula dentro da Universidade, é preciso que o acadêmico seja inserido no contexto profissional, saindo de práticas realizadas exclusivamente dentro do espaço físico formal, para atividades extramuros. A atividade extensionista fortalece o processo da interdisciplinaridade, ou seja, possibilita o encontro entre diferentes departamentos, o que é de suma importância para a formação do futuro cirurgião-dentista (GALASSI, 2006).

De acordo com o Plano Nacional de Extensão, publicado em 1999, a extensão universitária é o processo educativo, cultural e científico que articula o ensino e a pesquisa de forma indissociável e viabiliza a relação transformadora entre a Universidade e a sociedade. Para certificar a sua eficácia, o mesmo plano define também as diretrizes para a extensão universitária que devem estar presentes em todas as ações de extensão. São elas: impacto e transformação, interação dialógica, interdisciplinaridade, indissociabilidade ensino - pesquisa - extensão (FORPROEX, 2007).

Os cursos de Odontologia devem formar o acadêmico como um todo, um ser biológico, psíquico e cultural, que não deve se transformar apenas em um profissional, mas em um cidadão capaz de interagir com a sociedade (MADEIRA, 2006). Um projeto de extensão que envolve criança e adulto, família e escola e a comunidade em ambiente rural tem um alcance social muito importante, uma vez que promove prevenção e informação sobre as doenças mais prevalentes, como a cárie dentária, abrindo uma ampla interação entre Universidade e comunidade.

Sabóia et al. (2014) e Moimaz et al. (2015) constataram que a atividade extensionista gera acesso aos serviços odontológicos e esclarece o público-alvo sobre cuidados 
com a higiene bucal, assim como inova a aprendizagem do acadêmico baseando-se em conhecimento teóricoprático com metodologia de ensino inovadora.

Segundo Reses e Campos (2008), a saúde geral tem influência direta da saúde bucal, portanto, educar neste contexto mostra-se essencial para uma boa qualidade de vida. Saúde bucal é um conjunto de condições objetivas (biológicas) e subjetivas (psicológicas), que possibilita ao ser humano exercer funções como mastigação, deglutição e fonação e, também, tendo em vista a dimensão estética inerente à região anatômica, exercitar a autoestima e relacionar-se socialmente sem inibição ou constrangimento (NARVAI, 2001).

Além de ser de suma importância para a formação acadêmica, as atividades extramuros, ao nível de comunidades, também se mostram de grande valia para o público que abrange. Famílias com condições desfavoráveis de moradia e emprego tendem a ter menos acesso aos serviços de saúde e às ações de prevenção, procurando o atendimento, na maioria das vezes, quando a enfermidade já está instalada. Neste cenário, programas de promoção e prevenção de saúde, desenvolvidos pela comunidade acadêmica, são de grande valor para estas populações (PINTO, 1992). O grande desafio é promover saúde junto aos grupos sociais mais vulneráveis, cujas prioridades de sobrevivência estabelecem barreiras, que devem ser superadas, para a adoção de hábitos saudáveis em seus ambientes, capazes de tornar as escolhas saudáveis as mais fáceis (MOYSES; RODRIGUES, 2004). Essa mudança não se limita à assistência odontológica de qualidade, mas a incorpora como parte necessária desse processo, complementando o atendimento com atividades educativas que esclareçam à população sobre temas relacionados ao adoecimento e ao autocuidado, sem desconsiderar o direito à saúde.

A pobreza e desigualdade social formam um dos traços estruturais mais perversos da sociedade brasileira, não se restringindo às áreas rurais e mais remotas do país. $\mathrm{O}$ reconhecimento da vulnerabilidade de determinados grupos populacionais exige das instituições sociais, representadas pela Universidade, escola e serviços de saúde, um esforço integrado e intersetorial para contemplar o preceito constitucional da universalidade de acesso à saúde, resgatando os princípios da integralidade e da equidade como possibilidade de diminuir as injustiças sociais. Além disso, cada vez mais a epidemiologia da doença cárie vai se afastando de uma distribuição uniforme, sendo notados níveis crescentes de desigualdade e polarização de sua distribuição nas populações (PERES et al., 2008). Esse resultado demonstra a necessidade da inclusão da saúde bucal nas agendas da saúde pública, com garantia de acesso a uma assistência permanente e de qualidade, numa perspectiva integral, que inclua ações de promoção de saúde capazes de reverter um quadro epidemiológico tão grave e incompatível com os avanços da Odontologia.

Para Campostrini et al. (2015), projetos de extensão que possuem como público-alvo uma população de baixa renda são fundamentais para a formação de um profissional consciente das reais necessidades da região onde atuará. Concordam ainda que através das atividades extramuros o graduando pode praticar os ensinamentos adquiridos durante o curso em consonância com a realidade apresentada, tornando-se um profissional capaz de atuar com ética e profissionalismo.

Analisado este contexto e sabendo-se que a parceria entre a Universidade Regional de Blumenau (FURB), a Secretaria Municipal de Educação (SEMED) e a Secretaria Municipal da Saúde (SEMUS) de Blumenau contempla a educação continuada, o programa "FURBMóvel - Promovendo Saúde Bucal e Cidadania" oferece assistência odontológica aos escolares, idosos, pacientes com desordens psicossociais e usuários de álcool e drogas, além de capacitar os estudantes de Odontologia para o futuro profissional, ampliando os cenários de prática no ensino da área da saúde, para além dos muros da Universidade.

O objetivo deste artigo é apresentar o Programa de Extensão "FURBMóvel - Promovendo Saúde Bucal e Cidadania" desenvolvido pelo curso de Odontologia da FURB, ressaltando a prática de educação e saúde e de assistência bucal promovida em diferentes cenários de Blumenau, assim como discutir essas ações.

O Programa de Extensão "FURBMóvel - Promovendo Saúde Bucal e Cidadania" possui como público-alvo alunos de escolas do campo, alunos de escolas da rede municipal que participam do Programa Federal Mais Educação, idosos institucionalizados na Casa São Simeão e pacientes que frequentam o Centro de Atenção Psicossocial do Município de Blumenau (CAPS II e CAPS AD). Teve suas atividades iniciadas em março de 2007, estando hoje em sua décima edição anual. Foi proposto pela necessidade e importância de inverter as práticas mais comuns de atenção à saúde bucal, nas quais o paciente procura atendimento nos serviços de saúde, levando noções básicas de saúde bucal, promovendo ações de promoção e prevenção em saúde.

A proposta central do Programa é levar assistência odontológica e informações sobre saúde bucal ao encontro da população-alvo. $\mathrm{O}$ atendimento se dá dentro de um veículo fornecido pela Universidade (FURBMóvel) equipado com um consultório odontológico nos locais elegidos (Figuras 1 e 2). As atividades clínicas são aquelas referentes à atenção básica e vigilância em saúde bucal, capazes de controlar as doenças mais prevalentes, sendo: profilaxia, aplicação de flúor tópico, orientação individual para o controle de placa, tratamento restaurador atraumático (ART), restaurações de baixa complexidade, recontorno e polimento de restaurações, pequenos reparos de próteses, raspagem de cálculo e polimento coronário, sialometria induzida e diagnóstico de lesões bucais.

As ações de promoção de saúde são desenvolvidas por meio de atividades educativas com metodologias ativas específicas para a população alvo de cada projeto, buscando informá-los, conscientizá-los e motivá-los a realizarem o autocuidado em saúde tanto geral quanto bucal (Figura 3). Como elementos da estratégia metodológica para educação em saúde bucal, destacamse grupo focal (entrevistas com grupos, que tem como finalidade a coleta de informações por meio das 


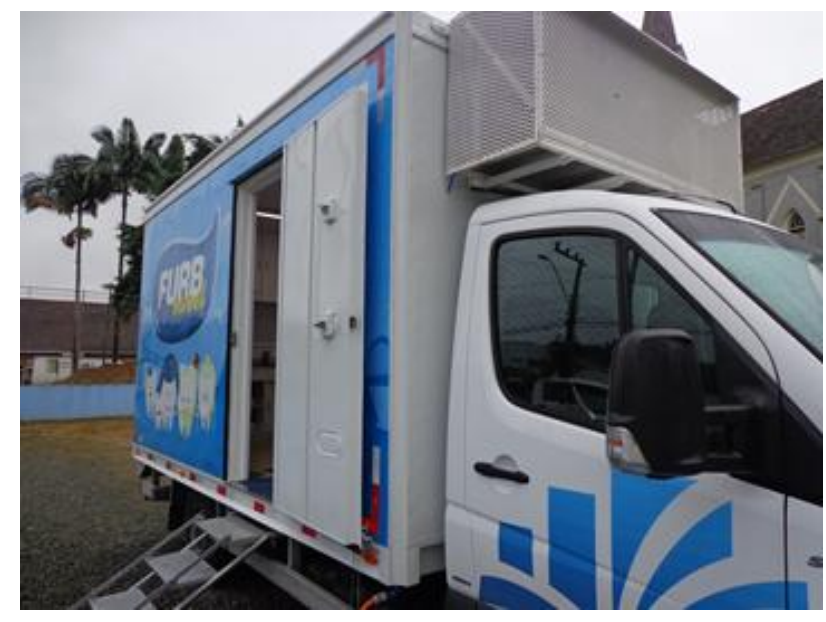

Figura 1. Veículo adaptado para atendimento odontológico.

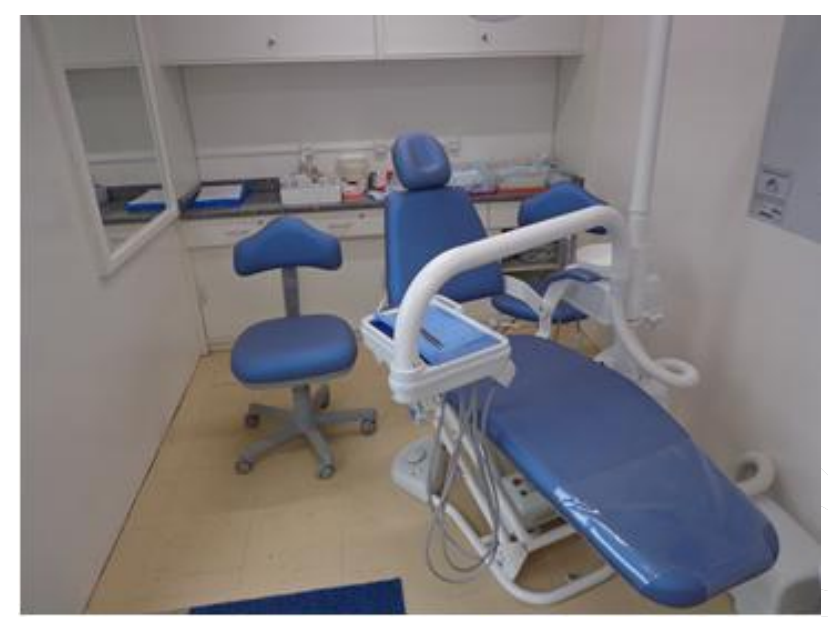

Figura 2. Consultório odontológico no interior do veículo.

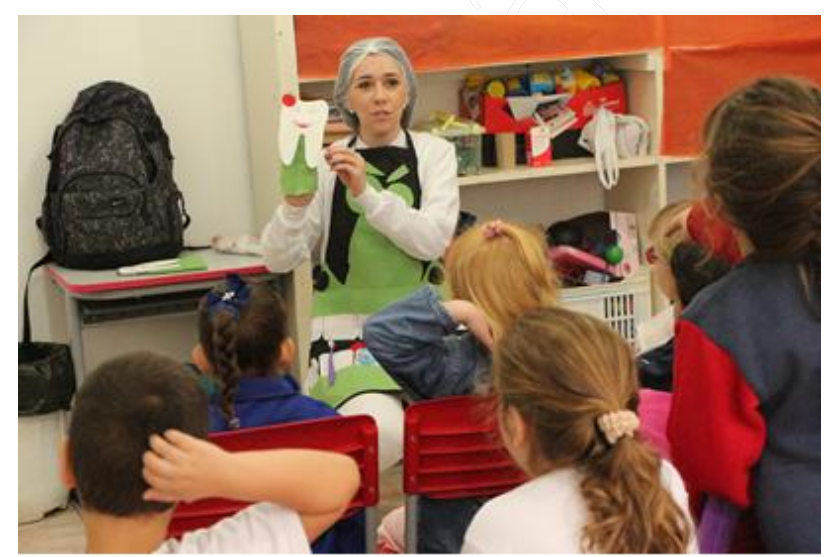

Figura 3. Ação educativa realizada pelos acadêmicos.

interações grupais), rodas de conversa, oficinas e palestras com utilização de recursos audiovisuais. Também são desenvolvidos materiais didáticos para abordar os temas propostos, como a criação de jogos, fantoches e histórias, com a finalidade de motivar o autocuidado e o controle de placa bacteriana realiza-se escovação supervisionada e a evidenciação de placa bacteriana.

A primeira etapa do Projeto consiste na seleção dos alunos bolsistas e voluntários. Para se candidatar a bolsista o aluno precisa estar cursando entre a $6^{\mathrm{a}}$ e $10^{\mathrm{a}}$ fase semestral do curso de Odontologia. Todos os acadêmicos das demais fases podem participar como voluntários. O Programa também oportuniza a interdisciplinaridade com a participação de acadêmicos de outros cursos da FURB da área da saúde (biomedicina, enfermagem, medicina, psicologia, farmácia, nutrição e educação física), ciências jurídicas (direito) e humanas (pedagogia e serviço social). Todas as atividades executadas pelos acadêmicos contam com a supervisão de um professor orientador.

Atualmente o Programa prevê dois alunos bolsistas. Aos bolsistas e alunos voluntários cabem: realização de pesquisa bibliográfica sobre os temas propostos para as abordagens, contribuição na elaboração de materiais didáticos (cartazes, folders, painéis) para subsidiar a abordagem, a participação nas atividades educativas, a realização das abordagens conforme planejamento pelas equipes, o registro da intervenção nos diários de campo e demais documentações, a participação na elaboração e apresentação de artigos e resumos para apresentação em eventos científicos.

Autores avaliaram a contribuição de um projeto de extensão que possui como público-alvo pacientes especiais na formação do acadêmico voluntário de Odontologia. Assim como acontece na maioria dos programas, o projeto não conseguiria gerar resultados quantitativos apenas com o trabalho dos bolsistas, sendo o trabalho voluntariado fundamental para o bom funcionamento das atividades. A longa permanência do acadêmico no projeto espelha a contribuição do mesmo na formação do estudante, mesmo sem a possibilidade de remuneração financeira (CASTILHO et al., 2014).

Após a definição das equipes, reuniões são realizadas para capacitação dos acadêmicos, previamente às saídas a campo. Juntamente com o professor orientador, discutese a melhor abordagem e linguagem a ser utilizada em cada faixa etária e público das ações. Realiza-se um planejamento com os temas que serão abordados e como serão desenvolvidos. Os temas comumente abordados são: importância da saúde bucal e sua relação com a saúde geral, escovação e uso de fio dental, dieta e sua relação com cárie dentária, cárie, placa bacteriana, flúor, hábitos indesejáveis (uso de chupetas, roer unhas, dedos, entre outros), traumatismo dentário (prevenção e condutas iniciais), doenças bucais, prevenção do uso de álcool e drogas e higienização de próteses.

Os projetos do Programa intitulam-se: "Atenção Básica em Saúde Bucal aos Alunos das Escolas do Campo do Município de Blumenau", "Projeto Educativo Preventivo em Traumatismos Dentários", "Promovendo saúde bucal e cidadania a pessoas com desordens mentais do CAPS II e CAPS AD de Blumenau", "FURBMÓVEL é Saúde e Mais Educação" e "Promoção de saúde dos idosos institucionalizados na Casa São Simeão: percepção de 
saúde bucal e edentulismo". Os projetos são desenvolvidos semanalmente, durante todo o semestre.

Os cinco projetos do Programa se articulam através de reuniões periódicas com toda a equipe, acadêmicos e professores, em formato de mesa redonda, onde se compartilham as experiências interdisciplinares vividas ao atuar como extensionista. Este espaço gera oportunidade para que acadêmicos extensionistas e professores orientadores de cada projeto troquem contribuições entre si, construam conhecimento e façam uma análise crítica dos saberes e práticas profissionais vigentes.

O tratamento puramente curativista em saúde pública passou a ser questionado a partir dos anos 60 e 70 (PINTO, 2000). Conhecimentos sobre o processo saúdedoença foram introduzidos no ensino do futuro profissional odontológico. Constatou-se que a doença cárie possui causa multifatorial, sendo necessário intervir não somente na doença, mas também nas suas causas para obter sucesso no tratamento. Neste contexto, ações de prevenção e promoção de saúde passaram a fazer parte das atividades acadêmicas em diversas disciplinas do curso de graduação em Odontologia e levadas à população.

Quando há uma interação entre o acadêmico e a comunidade vê-se uma inclusão social muito importante na vida acadêmica deste. A Universidade tem um importante papel para que este intercâmbio aconteça, promovendo projetos que englobem ações de Extensão, Pesquisa e Ensino. O curso de graduação deve utilizar metodologias que privilegiem a participação ativa do aluno na construção do conhecimento e promova a integração das dimensões biológicas, psicológicas, sociais e ambientais do processo saúde-doença (PEREIRA, 2003).

Existem dificuldades dentro dos cursos de Odontologia para a extensão se estabelecer como prática fundamental para a formação do futuro profissional. Ressaltam que são nas atividades extra-murais que as habilidades de promoção de saúde são adquiridas, contribuindo também para o contato entre o acadêmico e a comunidade, permitindo que $\mathrm{o}$ futuro profissional adquira conhecimentos socioculturais da sociedade que esta inserido (PEREIRA et al, 2011).

Criar e implementar estratégias que possibilitem a integração com as comunidades em seu entorno, transformando-as em participantes de projetos de mudança, inclusão social e desenvolvimento é o grande desafio que se coloca para os engajados na educação. É de suma importância ressaltar o papel da Universidade perante a sociedade, tornando possível a realização de uma reflexão critica para sua transformação, assim como possibilitar a materialização do princípio constitucional de indissociabilidade entre ensino, pesquisa e extensão (NUNES; SILVA, 2011).

Observa-se frequentemente que a interação que ocorre entre comunidade e Universidade, através da extensão universitária, leva os acadêmicos a construírem novos conhecimentos, muitas vezes diferentes e até mais elaborados e amplos no entendimento geral do processo saúde-doença, do que aquele produzido simplesmente dentro das quatro paredes das instituições universitárias, fornecendo um feedback de informações para estas promoverem uma maior pluralidade e flexibilidade à pesquisa e ao ensino, que ali se constroem, além de possibilitarem a formação de um profissional com visão mais ampliada de mundo (MENDES; MOURA; PRADO JÚNIOR, 2005).

Promover integração entre a Universidade e a Sociedade através de ações educativas, preventivas e curativistas permite que o acadêmico tenha contato com as reais condições de vida e saúde da população, possibilitando uma análise, reflexão das condições de saúde bucal e aprofundamento de seu conhecimento científico (CAPOTE, 1997). A formação do profissional do século XXI impõe a superação de uma visão puramente instrumentalista ou tecnicista do conhecimento, rejeitando os reducionismos inerentes à linearidade e fragmentação do saber (SOUSA SANTOS; ALMEIDA FILHO, 2008).

Por meio da extensão a comunidade acadêmica tem a possibilidade de, na sociedade, criar e vivenciar a prática do conhecimento adquirido, criando uma postura que vai além da formação profissional do estudante, adquirindo uma visão mais globalizada de conhecimento e criando seu papel enquanto sujeito social (MARTINS, 2008).

A associação entre o ensino, pesquisa e a extensão leva a mudanças significativas nos processos de ensino e de aprendizagem, fundamentando didática e pedagogicamente a formação profissional (DIAS, 2009). As atividades extramuros buscam a integração do ensino teórico com a vivência prática como uma forma de aprendizagem, permitindo ao acadêmico conhecer a organização, o planejamento e a gestão dos serviços de saúde da região (SANTOS et al., 2013). Além disso, também incentiva os acadêmicos a produzirem trabalhos para serem apresentados em jornadas cientificas e produção de artigos científicos para publicação. Através da criação do material didático que foi apresentado para o público, o acadêmico também explora seu lado criativo, desenvolvendo atividades lúdico-educativas para abordar os temas propostos.

O público externo também se beneficia, uma vez que o Programa atua levando informações teóricas e práticas sobre saúde bucal e aspectos envolvidos. Os procedimentos clínicos, além de tratar os problemas bucais, melhoram a autoestima do sujeito e o incentivam ao cuidado bucal. Torna-se notória a importância dos projetos de extensão, não só para o acadêmico, mas tão quanto para a comunidade, sendo um veículo de aprendizado para ambas as partes.

Levar noções básicas de saúde e motivar o autocuidado é um dos principais objetivos dos programas de extensão. Como afirmam Nunes et al. (2015), adquirir conhecimento sobre uma boa higiene bucal pode mudar significativamente a saúde bucal dos sujeitos, além de torná-los multiplicadores das ações de promoção de saúde em nível individual e coletivo. 


\section{Referências}

CAMPOSTRINI, V. L.; DE CARVALHO, R. B.; DAROZ, C. B. S.; DAROZ, L. G. D.; SARCINELLI, A.; BATITUCCI, R. Formação profissional em odontologia: contribuição do programa atendimento à saúde bucal para a população de baixa renda - Vitória-ES. Revista Guará, n. 3, p. 39-49, 2015.

CAPOTE, V. S. Relatório descritivo realizado no ano de 1997. Ponta Grossa: Universidade Estadual de Ponta Grossa, 1997.

CASTILHO, L. S.; ANKOMAA KASSIN, H.; PACHECO, A. R.; RESENDE, V. L. S. O trabalho voluntário e a educação do cirurgião-dentista: a experiência de um projeto de extensão odontológico. Em Extensão, v. 13, n. 2, p. 162-170, 2014.

DIAS, A. M. L. Discutindo caminhos para a indissociabilidade entre ensino, pesquisa e extensão. Revista Brasileira de Docência, Ensino e Pesquisa em Educação Física, v.1, n.1, p.37-52, 2009.

FORPROEX - Fórum de Pró-Reitores de Extensão das Universidades Públicas Brasileiras. Extensão Universitária: organização e sistematização. Organização: Edison José Corrêa. Coordenação Nacional do FORPROEX. - Belo Horizonte: Coopmed, 2007.

GALASSI, M. A. S.; BARBIN, E. L.; SPANÓ, J. C. E.; MELO, J. A. J.; TORTAMANO, N.; CARVALHO, A. C. Atividades extramuros como estratégia viável no processo ensino - aprendizagem. Revista da ABENO, v. 6, n. 1, p. 6669, 2006.

MADEIRA, M. C. Ensino, pesquisa e extensão. In: CARVALHO, A.C.P.; KRIGER L. Educação Odontológica. São Paulo: Artes Médicas, 2006, p. 97-103.

MARTINS, E. F. Extensão como componente curricular: oportunidade de formação integral e de solidariedade. Ciências \& Cognição, v. 13, n.2, p. 201-209, 2008.

MENDES, R. F.; MOURA, M. S.; PRADO JÚNIOR, R. R. Contribuição do estágio supervisionado da UFPI para a formação humanística, social e integrada. Revista da ABENO, v. 6, n. 1, p. 61-65, 2006.

MOIMAZ, S. A. S.; DE PAULA GOMES, A. M.; BORDIN, D.; GARBIN, C. A. S.; SALIBA, N. A. Extensão universitária como ferramenta geradora de ensino-aprendizagem e produtora de pesquisa. Revista Conexão da UEPG, vol. 11, n. 2, p. 140$149,2015$.

MOYSES, S. T.; RODRIGUES, C. S. Ambientes saudáveis: uma estratégia de promoção de saúde bucal de crianças. In: BONECKER, M.; SHEIHAM, A. (Orgs.) Promovendo saúde bucal na infância e adolescência: conhecimentos e práticas. São Paulo: Santos, 2004, p. 81-96.

NARVAI, P. C. Saúde bucal e incapacidade bucal. Jornal do Site Odonto, ano 3, n. 45, 2001. Disponível em: < http://www.jornaldosite.com.br/arquivo/anteriores/capel/artcap el10.htm >. Acesso em: 15 jun. 2015.

NUNES, A. L. P. F.; SILVA, M. B. C. A extensão universitária no ensino superior e a sociedade. Mal-Estar e Sociedade, v. 4, n. 7, p. 119-133, 2011.
NUNES, L. S. R.; GOMES, G. M.; DA SILVA JUNIOR, L. G.; SANTOS, M. D. C. S.; MIRANDA, R. S.; EVANGELISTA, L. M. Teia de aranha: uma visão criativa em saúde bucal. Revista Eletrônica Gestão \& Saúde, v. 6 (supl. 1), p. 793-799, 2015.

PEREIRA, S. M.; MIALHE, F. L.; PEREIRA, L. J.; SOARES, M. D. F.; TAGLIAFERRO, E. P. D. S.; MENEGHIM, M. D. C.; PEREIRA, A. C. Extensão universitária e trabalho voluntário na formação do acadêmico em Odontologia. Arquivos em Odontologia, v. 47, n. 2, p. 95-103, 2011.

PEREIRA, A. C. Odontologia em Saúde Coletiva: Planejando Ações e Promovendo Saúde. Porto Alegre: ARTMed, 2003.

PERES, S. H. D. C. S.; CARVALHO, F. S. D.; CARVALHO, C. P. D.; BASTOS, J. R. D. M.; \& LAURIS, J. R. P. Polarization of dental caries in teen-agers in the Southwest of the state of São Paulo, Brazil. Ciência \& Saúde Coletiva, v. 13, p. 2155-2162, 2008.

PINTO, V. G. Saúde Bucal: Odontologia Social e Preventiva. 3. ed. São Paulo: Santos, 1992.

PINTO, V. G. Saúde bucal coletiva. 4. ed. São Paulo: Santos, 2000.

RESES, S. L. N.; CAMPOS, M. L. Condições de saúde bucal em idosos institucionalizados e necessidades de educação em práticas de saúde bucal para cuidadores de idosos. 2008. Trabalho de Conclusão de Curso (Especialização em Gestão dos Serviços de Saúde) Universidade para o Desenvolvimento do Alto Vale do Itajaí, Rio do Sul, 2008.

SABÓIA, V. D. P. A.; RODRIGUES, N. S.; GOMES FONTENELE, G. Y.; SILVA, A. P. V.; NOGUEIRA, C. S.; CABRAL FILHO, R. E. Programa odontológico preventivo para gestantes adolescentes - projeto sorridente: relato de experiência. Extensão em Ação, v. 2, n. 7, p. 140-152, 2014.

SANTOS, K. T.; FERREIRA, L.; BATISTA, R. J. Percepção discente sobre a influência de estágio extramuros na formação acadêmica odontológica. Revista de Odontologia da UNESP, v. 42, n. 6, p. 420-425, 2013.

SOUSA SANTOS, B.; ALMEIDA FILHO, N. A Universidade no Século XXI: Para uma Universidade Nova. Coimbra: Almedina, 2008.
Como citar este artigo:

OLIVEIRA, A.; SCHARF, D.; OLIVEIRA, M. F.; SCHLINDWEIN, C. H.; RASTELLI, M. C. S.; DE ANDRADE, I. C. G. B. Odontologia itinerante na extensão universitária: FURBMóvel - promovendo saúde bucal e cidadania. Revista Brasileira de Extensão Universitária, v. 7, n. 1, p. 37-42, 2016. Disponível em: $<$ https://periodicos.uffs.edu.br/index.php/RBEU/article /view/3085/pdf > 